\title{
Influence of Computerised Medication Charts on Medication Errors in a Hospital
}

\author{
Dieuwke G. van Gijssel-Wiersma, ${ }^{1,2}$ Patricia M.L.A van den Bemt ${ }^{3,4}$ and \\ Monique C.M. Walenbergh-van Veen ${ }^{1}$ \\ 1 Hospital Pharmacy, Groene Hart Hospital, Gouda, The Netherlands \\ 2 Hospital Pharmacy, Slingeland Hospital, Doetinchem, The Netherlands \\ 3 Hospital Pharmacy Midden-Brabant, TweeSteden Hospital and St Elisabeth Hospital, Tilburg, \\ The Netherlands \\ 4 Utrecht Institute for Pharmaceutical Sciences (UIPS) - Department of Pharmacoepidemiology \\ and Pharmacotherapy, Utrecht University, Utrecht, The Netherlands
}

\section{Abstract}

Introduction: In hospitals where computerised physician order entry systems will not be available in the near future, there is a need to explore other ways of reducing medication errors that occur in the drug ordering and delivery system. One of these ways is the use of a computerised medication chart that is updated daily. The aim of this study was to evaluate the frequency, types and potential clinical significance of drug prescription and administration errors by comparing a traditional medication distribution system (where the transcription of handwritten into printed medication orders takes 3-5 days and the transfer of medication orders was not complete) with the use of a computerised medication chart (which was updated daily by pharmacy assistants on the ward).

Methods: Data were collected during two 3-week periods, from a 32-bed internal medicine unit, before and after the introduction of the computerised medication charts. Prescribing errors were observed by evaluation of all new and changed medication orders and administration errors were detected by using the disguised-observation technique.

Results: For prescribing errors, a total of 611 prescriptions before and 598 prescriptions after the intervention were evaluated. The total prescription error rate (of medication orders with $\geq 1$ error) was found to be significantly higher with the computerised charts when compared with the old system (50.0\% [299 of 598] vs $20.3 \%$ [124 of 611], odds ratio [OR] 3.80 [95\% CI 2.94, 4.90]). This increase was caused by an increase in administrative prescription errors with a low potential clinical significance (mainly omission of the prescriber's name and the prescription date). The error rate for errors with a potential clinical significance was found to be significantly lower because the prescription error 'duplicate therapy' was eliminated $(3.4 \%$ with the traditional medication chart vs $0 \%$ with the computerised chart). For administration errors, a total of 1122 drugs before the intervention and 1175 drugs after the intervention was observed to be administered. The total administration error rate was found to be significantly lower after the intervention $(6.1 \%$ [ 72 of 1175] vs $10.5 \%$ [118 of 1122], OR 0.61 [95\% CI $0.45,0.84])$, as was the error rate with a potential clinical significance. The contribution of handwritten medication orders to the total amount of medication 
orders was significantly decreased after the intervention (12.8\% vs $20.6 \%$ [95\% CI 4.6, 11.0]) and the administration of a drug ordered by a handwritten medication order resulted in a significantly higher administration rate than with administration of a drug ordered by a printed medication order (before the intervention $20.7 \%$ vs $8.0 \%$, OR 2.99 [95\% CI 1.96, 4.56], after the intervention $11.4 \%$ vs $5.6 \%$, OR 2.18 [95\% CI 1.16, 4.11]).

Conclusion: This observational study shows a significant reduction in clinically relevant, administration and (therapeutic) prescription error rates when applying a system using computerised and daily updated medication charts compared with a system using traditional medication charts. Therefore, the use of computerised and daily updated medication charts has the potential to improve the quality of the medication distribution process in hospitals waiting for the implementation of a computerised physician order entry system.

\section{Introduction}

In recent years there has been an increasing interest in medication safety. The report 'To err is human' has drawn attention to the occurrence, clinical consequences and costs of medication errors. ${ }^{[1]}$ They are associated with a substantial increase in patient morbidity and mortality. ${ }^{[1-3]}$

Medication errors are defined as errors in the distribution process of medication, regardless of whether an injury actually occurred or the potential for injury was present. ${ }^{[4]}$ Medication errors can occur at any stage in the drug prescribing, dispensing and administration process. ${ }^{[5,6]}$ Many of these errors are caused by system failures. ${ }^{[7]}$

Most hospitals in The Netherlands use a traditional medication distribution system in which the medication orders are collected by the pharmacy and then entered into a computer. The physician writes the medication order manually on multicopy order sheets and the orders are interpreted and entered into the pharmacy computer system by pharmacy assistants. Order entry accuracy is checked by another pharmacy assistant. After this transcription, a printed medication order is generated. A copy of the handwritten medication order is placed in the medication chart of the patient on the ward. When a printed order is received from the pharmacy, it replaces the handwritten medication order on the medication chart. The medication chart is used by nurses to prepare and dispense the medication and to record the administration of the drugs (figure 1). The medication chart is the equivalent of the medication administration record in the US.
In our hospital replacement of the handwritten medication orders by printed ones usually takes 3-5 days. Sometimes the handwritten medication orders or changes in the orders are not received by the pharmacy at all. It is known that handwritten medication orders require more time to be interpreted by the pharmacy and to be administered by the nurses. ${ }^{[4]}$ In order to save time and reduce medication errors the development and use of computerised physician order entry (CPOE) systems are highly recommended. In the Groene Hart Hospital the introduction of a physician order entry system was not expected in the near future. Therefore, other ways of improving the drug ordering and delivery system have had to be explored, awaiting the introduction of a CPOE system. One of these ways is the use of a computerised medication chart that is updated daily. Medication prescribing, delivering and administration will occur within the same computerised medication chart. The physician handwrites orders directly onto the medication chart. Within 1 day new, changed or terminated medication orders are interpreted and entered into the pharmacy computer system by pharmacy assistants and a new computerised medication chart is generated. So this chart only contains current medication orders and, in contrast to the traditional medication chart, is not mixed with terminated medication orders (figure 2). Instead, a short overview of the patient's previous medications is included at the end of the list.

This system is thought to be less error prone than the traditional system, but this has never been proven. Therefore, we set up a study to evaluate the 


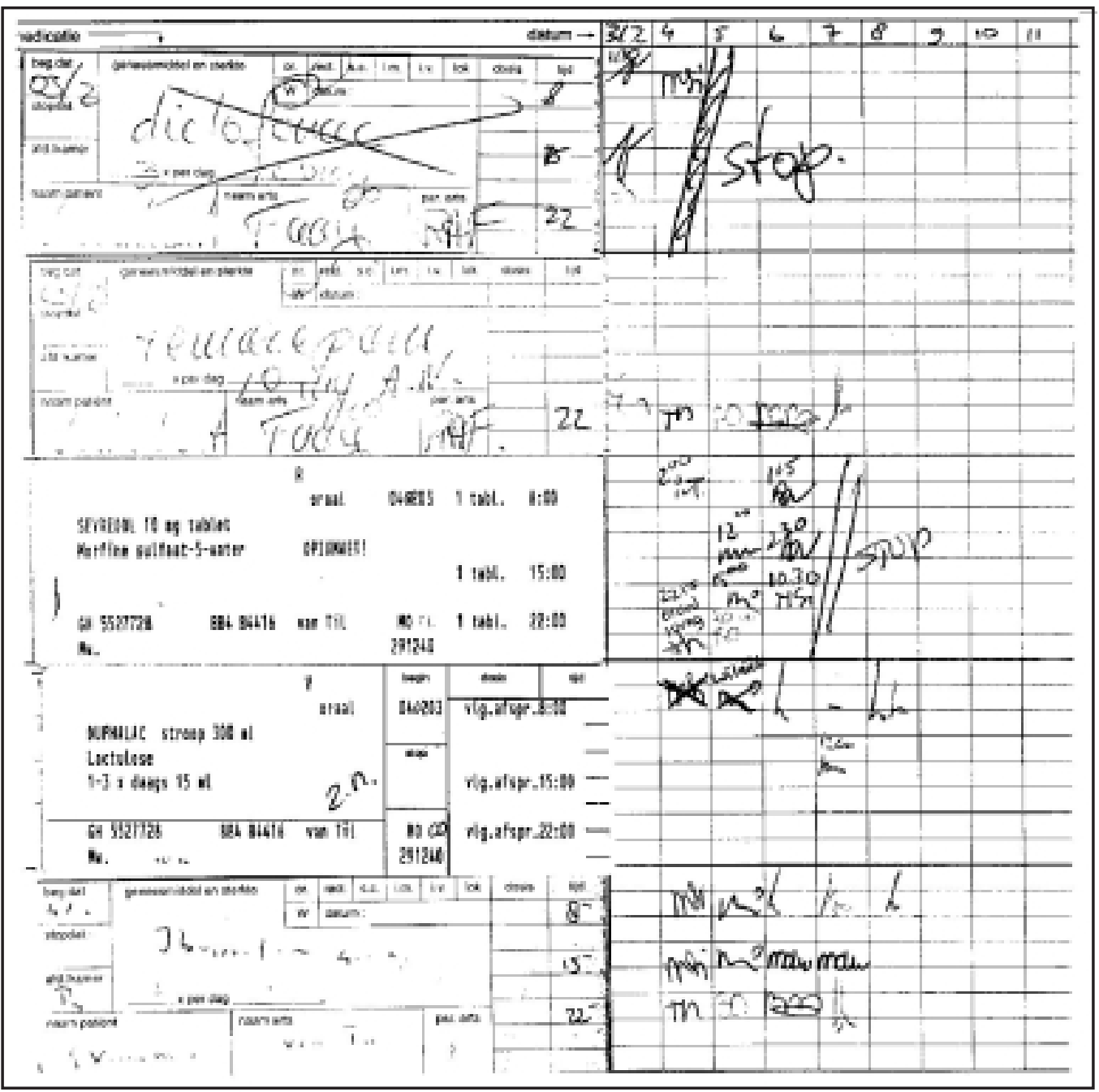

Fig. 1. A traditional medication chart.

effect of a system using computerised, daily updated medication charts on the frequency, type and potential clinical significance of prescribing and administration errors.

\section{Methods}

\section{Setting}

The Groene Hart Hospital, a 500-bed general hospital in Gouda, The Netherlands, uses the pharmacy computer system Centrasys-ZA (Thorex-
Hiscom). All known medication orders are entered in this computer system by pharmacy assistants. Using the traditional medication chart the written medication orders must be sent to the pharmacy by nurses. When using the computerised medication charts the pharmacy assistants go to the ward daily to gather all new and changed medication orders. After these medication orders are entered into the computer, the computer system automatically performs safety checks on under- and overdose, drugdrug interactions and duplicate medication. Finally a 


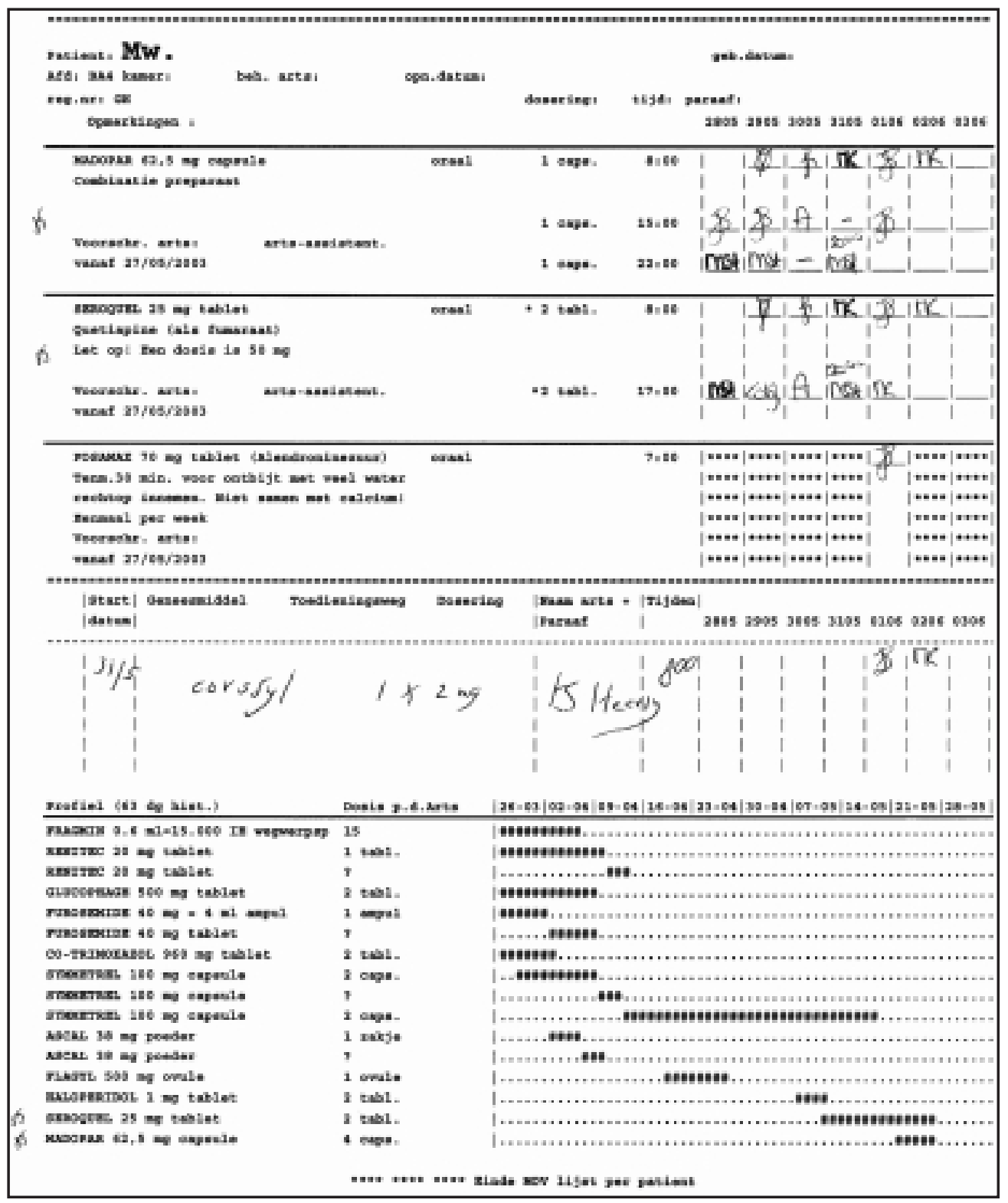

Fig. 2. A computerised medication chart that is updated daily.

new computerised medication chart is printed for use on the ward.

This prospective observational study was carried out in a 32-bed internal medicine unit (internal medicine, geriatric medicine and dialysis). During the study period the medical staff consisted of 2 physicians, 2 physician assistants, 32 nurses (24 registered and 8 student nurses). With the exception of one physician assistant, the medical staff in the pre- and postintervention period did not change. The use of the traditional medication chart system was observed during 3 weeks in February 2003. The new computerised and daily updated medication charts 
were introduced in March 2003. The use of this system was observed during 3 weeks in June 2003.

\section{Detection of Prescription Errors}

All new and changed medication orders during both study periods were evaluated by one observer.

Prescription errors were defined as any error in the prescription of the patient's name, drug's name, strength, dose, form, route or dose frequency, prescriber's name, prescription date or any omission of these prescribing items or missing critical information, including inappropriate combination of drugs, under- and overdose and drug-drug interaction.

When clarification on a prescription error was necessary for transcription in the pharmacy computer, the pharmacy assistant or pharmacist contacted the physician or nurse, depending on the relevancy of the error. This feedback took place within standard procedures that were independent of this study. The impact on future prescriptions was the same in the pre- and postintervention period.

Errors in the choice of drug according to standards of practice, inappropriate indication for use, contraindicated therapy and documented allergies to ordered medication were not evaluated.

\section{Detection of Administration Errors}

Administration errors were detected by using the disguised-observation technique. ${ }^{[8]}$ One observer followed the nurses preparing and administering drugs during the drug rounds of $8 \mathrm{am}$ and $3 \mathrm{pm}$. The observer wrote down exactly what the nurses did during the preparation and administration of medication. Afterwards, the observations were compared with the original medication orders and with the general hospital protocols (for administration of parenteral drugs or drugs through a gastric feeding tube).

An administration error was defined as any deviation between prescribed and actually administered drugs and/or deviation from the general hospital protocols.

Nurses were unaware of the goal of the study; they were told that the observer came to study the drug distribution system. During the implementation of the new system using computerised medica- tion charts, the nurses were informed how to use these medication charts. There was no concomitant teaching on medication safety or another form of education.

The observer was a hospital pharmacist. In order to become familiar with the regular proceedings in the internal medicine unit, the observer underwent a 3-day training period. During this period the observer also became familiar with the technique of disguised observation.

\section{Classification and Frequency}

Prescribing and administration errors were classified according to the national guidelines of the Dutch Association of Hospital Pharmacists (NVZA). ${ }^{[9]}$

A wrong-time error was defined as administration of a drug at least 60 minutes early or late.

The frequency of prescribing errors was defined as the sum of prescribing errors divided by the total number of prescribed drugs, with the possibility of having more than one prescribing error per prescribed drug.

The frequency of administration errors was defined as the sum of administration errors divided by the sum of observed administered drugs (whether ordered or not) and omitted drugs, with a maximum of one administration error per administered drug.

The error frequencies were reported as percentages.

\section{Potential Clinical Significance}

The potential clinical significance of each observed administration error was classified into one of five categories of seriousness derived from The National Coordinating Council for Medication Error Reporting and Prevention (NCCMERP) taxonomy of medication errors. ${ }^{[10]}$ The categories are as follows:

- category A: an error has been made, but the error did not reach the patient;

- category B: an error has been made and did reach the patient, but probably no harm is done;

- category C: an error has been made that probably causes harm to the patient;

- category D: an error has been made that causes harm to the patient; 
- category E: an error has been made that probably results in the death of the patient.

For the classification of the potential clinical significance of prescription errors, category A included the administrative prescription errors, which were divided into:

- A0: prescriber's name or date is missing;

- A1: prescription errors with trivial errors about which no misunderstanding is possible;

- A2: prescription errors that require clarification before administration is possible.

The potential clinical significance of each observed prescribing and administration error was evaluated independently by two hospital pharmacists. When the reviewers disagreed about the classification, they met to reach consensus.

\section{Statistical Analysis}

Sample size was calculated, assuming a reduction in prescription error frequency from $10 \%$ to $5 \%$, using $\alpha=0.05$ and a power of $80 \%$. This resulted in a sample size of 400 medication orders that had to be observed during both study periods. For a reduction in administration error frequency from $6 \%$ to $3 \%$, 750 medication administrations had to be observed during both study periods.

All variables were entered into a database (MS Access 2000). The data were analysed using SPSS 10. Univariate analyses were carried out using the Chi-squared test for dichotomous variables and the two sample t-test for continuous variables. Multivariate logistic regression was used for assessing the influence of the confounders 'registered versus student nurse' and 'written versus printed medication order' on administration errors. Results are presented as odds ratio (OR) and $95 \%$ CI.

\section{Results}

Drug prescription and administration for 81 patients in the preintervention period and 95 patients in the postintervention period was observed. Patient characteristics are summarised in table I. Both groups were not significantly different with respect to age, sex and length of hospital stay, although there was a trend to a shorter length of hospital stay in the postintervention period.

The types of prescriptions and administrations (form, route and drug class) in the pre- and postintervention period were comparable.

Within the total amount of evaluated running medication orders, the contribution of handwritten medication orders was significantly lower with the computerised charts than with the old system $(12.8 \%$ vs $20.6 \%, 95 \%$ CI $4.6,11.0)$. Printed medication orders had a duration of 16.0 days before and 13.4 days after the intervention. The time span in which handwritten medication orders were replaced by printed orders was found to be significantly shorter after the intervention compared with before the intervention (1.9 days vs 6.9 days, $95 \%$ CI 2.99 , 7.02 [t-test]).

\section{Prescription Errors}

Before and after the intervention 611 and 598 medication orders, respectively, were evaluated for prescription errors. The error rates identified are summarised in table II. The total prescription error rate (of medication errors with $\geq 1$ error) was found to be significantly higher after the intervention $(50.0 \%$ vs $20.3 \%)$. This is due to an increase in administrative prescription errors with a low potential clinical significance. Consequently, the error rate with a potential clinical significance category A0 was significantly higher after the intervention (table III).

Table I. Patient characteristics

\begin{tabular}{llll}
\hline Characteristic & Preintervention group & Postintervention group & p-Value \\
\hline Number of patients & 81 & 95 & \\
Percentage of males $^{\mathrm{a}}$ & 45.7 & 37.9 & 0.296 \\
Mean age in years (SD) $^{\mathrm{a}}$ & $70.6(17.2)$ & $73.2(14.6)$ & 0.288 \\
Length of hospital stay in days $^{\mathrm{b}}$ & $26.5(32.3)$ & $19.6(22.1)$ & 0.100 \\
\hline $\mathrm{a} \quad$ Chi-squared test. & & & \\
b t-Test. & & & \\
\hline
\end{tabular}


Table II. Frequency and types of prescription errors

\begin{tabular}{|c|c|c|c|c|}
\hline Prescription error types & $\begin{array}{l}\text { Frequency of } \\
\text { errors for system } \\
\text { with traditional } \\
\text { medication chart } \\
\text { (no. of errors) }\end{array}$ & $\begin{array}{l}\text { Frequency of } \\
\text { errors for system } \\
\text { with computerised } \\
\text { medication chart } \\
\text { (no. of errors) }\end{array}$ & $\begin{array}{l}\text { Odds ratio } \\
(95 \% \mathrm{Cl})^{\mathrm{a}}\end{array}$ & Example \\
\hline \multicolumn{5}{|l|}{ Administrative errors } \\
\hline Overall & $13.4(82)$ & $53.3(319)$ & $7.38(5.56,9.79)$ & \\
\hline general & $0.3(2)$ & $0.0(0)$ & b & Illegible medication order \\
\hline patient & $0.8(5)$ & $1.8(11)$ & $2.27(0.78,6.58)$ & Patient name missing \\
\hline prescriber & $1.3(8)$ & $21.1(126)$ & $20.1(9.75,41.5)$ & Prescriber's name missing \\
\hline drug & $1.6(10)$ & $2.5(15)$ & $1.55(0.69,3.47)$ & Just 'vitamin' without specification \\
\hline form/route & $3.6(22)$ & $9.0(54)$ & $2.66(1.60,4.42)$ & $\begin{array}{l}\text { Just 'depakine [valproic acid] } 500 \mathrm{mg} \text { ' } \\
\text { without dose form and route }\end{array}$ \\
\hline prescription date & $5.7(35)$ & $18.9(113)$ & $3.83(2.58,5.71)$ & Prescription date missing \\
\hline \multicolumn{5}{|l|}{ Dosing errors } \\
\hline Overall & $7.0(43)$ & $7.5(45)$ & $1.08(0.70,1.66)$ & \\
\hline strength & $2.8(17)$ & $4.3(26)$ & $1.59(0.85,2.96)$ & 'Glucophage [metformin] 580mg' \\
\hline frequency & $2.3(14)$ & $1.0(6)$ & $0.43(0.17,1.13)$ & Frequency missing \\
\hline overdosing & $0.2(1)$ & $0.3(2)$ & $2.05(0.19,22.6)$ & 'Cisapride 3 × 20mg' \\
\hline $\begin{array}{l}\text { maximum daily dose } \\
\text { missing }\end{array}$ & $1.6(10)$ & $1.2(7)$ & $0.71(0.27,1.88)$ & 'Morphine as needed' \\
\hline underdosing & $0.0(0)$ & $0.2(1)$ & b & $\begin{array}{l}\text { Isosorbide dinitrate ointment for anal } \\
\text { use three times daily }\end{array}$ \\
\hline instructions for use & $0.2(1)$ & $0.5(3)$ & $3.07(0.32,29.7)$ & $\begin{array}{l}\text { Eyedrops without specification } \\
\text { left or right }\end{array}$ \\
\hline \multicolumn{5}{|l|}{ Therapeutic errors } \\
\hline Overall & $4.9(30)$ & $0.8(5)$ & $0.16(0.06,0.42)$ & \\
\hline drug-drug interaction & $1.5(9)$ & $0.8(5)$ & $0.56(0.19,1.69)$ & $\begin{array}{l}\text { Levothyroxine and ferrous fumarate } \\
\text { at the same time }\end{array}$ \\
\hline duplicate therapy & $3.4(21)$ & $0.0(0)$ & $0.05(0.01,0.35)^{c}$ & $\begin{array}{l}\text { Second MO for 'acetylsalicylic acid } \\
\text { [aspirin] } 80 \mathrm{mg} \text { ' }\end{array}$ \\
\hline Total prescription error rate & $25.4(155 / 611)$ & $61.7(369 / 598)$ & $4.74(3.71,6.06)$ & \\
\hline Rate of MOs with $\geq 1$ error $^{d}$ & $20.3(124 / 611)$ & $50.0(299 / 598)$ & $3.80(2.94,4.90)$ & \\
\hline \multicolumn{5}{|c|}{ a Odds ratio $(95 \% \mathrm{Cl})$ Chi-squared test. } \\
\hline \multicolumn{5}{|c|}{ b Odds ratio can not be calculated because of zero value during one of the study periods. } \\
\hline \multicolumn{5}{|c|}{$\begin{array}{l}\text { c Odds ratio calculated by approach by taking a value of one instead of zero. } \\
\text { d One prescription may involve multiple errors. }\end{array}$} \\
\hline \multicolumn{5}{|c|}{ d One prescription may involve multiple errors. } \\
\hline \multicolumn{5}{|c|}{ MO = medication order. } \\
\hline
\end{tabular}

The prescription error rate 'duplicate therapy' showed a significant reduction after intervention ( $0 \%$ vs $3.4 \%$ ). Mainly because of this reduction, the error rate with a potential clinical significance catergory $\mathrm{C}$ was significantly lower after the intervention.

\section{Administration Errors}

Before and after the intervention, the administration of 1122 and 1175 drugs, respectively, was observed. Administration error rates identified are summarised in table IV. The total administration error rate was significantly lower after the intervention $(6.1 \%$ vs $10.5 \%)$. Also, the error rate with a potential clinical significance category $\mathrm{C}$ was significantly lower after the intervention (table V).

Administration of a drug from a handwritten medication order resulted in a significantly higher administration error rate than with administration from a printed medication order (before the intervention $20.7 \%$ vs $8.0 \%$, OR 2.99 [95\% CI 1.96, 4.56]), after the intervention $11.4 \%$ vs $5.6 \%$, OR 2.18 [95\% CI 1.16, 4.11]). 
Table III. Potential clinical significance of prescription errors

\begin{tabular}{|c|c|c|c|c|}
\hline Category $^{\mathrm{a}}$ & $\begin{array}{l}\text { Frequency of errors for system } \\
\text { with traditional medication chart } \\
\text { (no. of errors) }\end{array}$ & $\begin{array}{l}\text { Frequency of errors for system } \\
\text { with computerised medication } \\
\text { chart (no. of errors) }\end{array}$ & $\begin{array}{l}\text { Odds ratio } \\
(95 \% \mathrm{Cl})^{\mathrm{b}}\end{array}$ & Example \\
\hline $\mathrm{AO}$ & $7.0(43)$ & $39.8(238)$ & $8.73(6.15,12.4)$ & $\begin{array}{l}\text { Prescriber's name or date } \\
\text { missing }\end{array}$ \\
\hline A1 & $3.6(22)$ & $8.2(49)$ & $2.22(1.15,4.97)$ & $\begin{array}{l}\text { 'Oxazepam 10mg' without form/ } \\
\text { route }\end{array}$ \\
\hline A2 & $7.4(45)$ & $10.4(62)^{a}$ & $1.35(0.91,2.00)$ & Patient name missing \\
\hline B & $1.5(9)$ & $1.0(6)$ & $0.68(0.24,1.92)$ & $\begin{array}{l}\text { 'Paracetamol [acetaminophen] } \\
500 \text { mg as needed' without } \\
\text { maximum dose }\end{array}$ \\
\hline C & $4.9(30)$ & $1.0(6)$ & $0.20(0.08,0.48)$ & $\begin{array}{l}\text { Norfloxacin and ferrous fumarate } \\
\text { at the same time }\end{array}$ \\
\hline D & $1.0(6)$ & $1.3(8)$ & $1.37(0.47,3.96)$ & 'Digoxin $0.25 \mathrm{mg}$ twice daily' \\
\hline Total & $25.4(155 / 611)$ & $61.7(369 / 598)$ & & \\
\hline a See & (al & 1 the & & \\
\hline
\end{tabular}

\section{Discussion}

Several studies on medication errors have been carried out in the past years. Most of these are studies in which frequencies and determinants of medication errors are identified. ${ }^{[5]}$ Relatively few observational studies have been carried out into the effect of interventions to reduce errors. One of those interventions is pharmacist participation with the medical rounding team. On a general medicine unit or intensive care unit, this was found to be associated with a substantially lower rate of adverse drug events. ${ }^{[11,12]}$ CPOE systems are another evidencebased intervention for error reduction. ${ }^{[13]}$ Although CPOE systems are not yet available for most hospitals, there is a need for studies on the effect of other interventions within the drug prescribing, dispensing and administration process. Therefore, the results of our study, which showed the effect on the prescription and administration error rate of an intervention concerning the medication charts, can be useful in everyday practice.

Surprisingly, our intervention aimed at reducing errors resulted in a large increase in the total prescription error rate. This was due to the amount of administrative prescription errors ( 82 vs 319 of all prescription errors) that are mainly omissions. The prescriber's name or signature and the prescription date were the most frequent omissions. As opposed to the traditional handwritten prescriptions, there are no specific input fields for the medication orders written on the computerised medication chart.
Therefore, these items are easily forgotten when prescribing drugs on the new charts. Fontan et al. ${ }^{[14]}$ showed a significant decrease in omissions when using an electronic prescription system (from $76.7 \%$ to $3.4 \%$ of all errors). Using this system, these fields were mandatory to fill out. Editing the layout of the printed medication charts in our hospital would probably be helpful in limiting the number of administrative errors.

In spite of the increase of the total amount of prescription errors, the amount of errors with a potential clinical significance was decreased (from $5.9 \%$ to $2.3 \%$ ). This was mainly due to the decrease of the prescription error 'duplicate therapy'. Probably because the computerised medication chart gives a clear overview of all running medication orders, this type of error was reduced.

Dean et al. ${ }^{[15]}$ found $1.5 \%$ (538 of 35866 ) of all prescription errors to be more or less serious and Lesar et al. ${ }^{[16]}$ found a rate of $0.18 \%$ (522 of 289411 ) for clinically significant prescription errors. However, these results are difficult to compare with ours, because in these studies far more medication orders were evaluated.

European or American observational studies of medication administration errors show total administration error rates that vary between $2.4 \%$ and $44.6 \% .^{[7,14,17-19]}$ The total administration error rate in our study decreased from $10.5 \%$ to $6.1 \%$ when the computerised medication charts were implemented. It is difficult to compare these results because the 
setting (adult intensive care unit or general ward), the drug distribution system (unit dose or ward stock) and method of detection (medical record analysis or disguised or not disguised observation) are different.

The main type of administration error in both study periods of our study was an omission error. Most of the omitted drugs were either from the ward stock that were out of supply or were non-stock drugs that were not available in the pharmacy. This was also seen by Taxis et al. ${ }^{[18]}$ In contrast to the literature we found a small amount of time errors (1.9\% and $0.6 \%$ in this study vs up to $26 \%$ in other studies). ${ }^{[7,14,17]}$

The amount of administration errors with a potential clinical significance was reduced (from 3.7\% to $1.1 \%$ ). There is no main error responsible for this result. Almost all types of administration errors decreased after the implementation of the computerised medication chart.

The expectation that the frequency of administration errors using handwritten medication orders is higher than with printed medication orders is confirmed in this study. It is obvious that the new system of gathering the medication orders daily by the pharmacy assistants provides a lower amount and a shorter running time of handwritten medication orders. However, after correction for this difference in the multivariate logistic regression model the frequency of administration errors remained significantly lower with the computerised medication charts.

It was observed in the postintervention period that relatively more drugs were administered by registered nurses than by student nurses. For this difference an adjustment was made in the multivariate logistic regression model.

The evaluation of administration errors was based on the disguised-observation technique. This technique has been estimated as superior to medical record review and to examination of incident reports. ${ }^{[20]}$ It was established that using this technique did not significantly affect the rate of medication administration errors. ${ }^{[21]} \mathrm{A}$ limitation of this study is the fact that the observer was not blinded, i.e. that the observer was aware of whether the observation took place in the pre- or postintervention period. Because the observer compared the administered drugs with the original orders, blinding of the used system was not feasible. However, the observer only

Table IV. Frequency and types of administration errors

\begin{tabular}{|c|c|c|c|c|}
\hline $\begin{array}{l}\text { Administration error } \\
\text { types }\end{array}$ & $\begin{array}{l}\text { Frequency of errors for } \\
\text { system with traditional } \\
\text { medication chart (no. of } \\
\text { errors) }\end{array}$ & $\begin{array}{l}\text { Frequency of errors for } \\
\text { system with computerised } \\
\text { medication chart (no. of } \\
\text { errors) }\end{array}$ & $\begin{array}{l}\text { Odds ratio } \\
(95 \% \mathrm{Cl})^{\mathrm{a}}\end{array}$ & Example \\
\hline Omission error & $5.1(57)$ & $3.9(46)$ & $0.85(0.56,1.28)$ & $\begin{array}{l}\text { Paracetamol (acetaminophen) } \\
\text { omitted }\end{array}$ \\
\hline Unordered drug error & $0.5(6)$ & $0.0(0)$ & $\mathrm{b}$ & Oxazepam instead of diazepam \\
\hline Wrong dose form error & $0.2(2)$ & $0.8(9)$ & $4.55(0.98,20.0)$ & $\begin{array}{l}\text { Isosorbide dinitrate extended } \\
\text { release } 20 \mathrm{mg} \text { crushed for } \\
\text { administration by gastric feeding } \\
\text { tube }\end{array}$ \\
\hline Wrong route error & $0.5(6)$ & $0.0(0)$ & $\mathrm{b}$ & $\begin{array}{l}\text { Omeprazole } 40 \mathrm{mg} \text { intravenous } \\
\text { instead of oral }\end{array}$ \\
\hline $\begin{array}{l}\text { Wrong administration } \\
\text { technique error }\end{array}$ & $1.1(12)$ & $0.4(5)$ & $0.43(0.15,1.23)$ & $\begin{array}{l}\text { Esomeprazole crushed for } \\
\text { administration by gastric feeding } \\
\text { tube instead of dissolving in } \\
\text { water }\end{array}$ \\
\hline Wrong dose error & $1.2(14)$ & $0.4(5)$ & $0.33(0.12,0.95)$ & $\begin{array}{l}\text { Potassium chloride solution } 30 \mathrm{~mL} \\
\text { instead of } 15 \mathrm{~mL}\end{array}$ \\
\hline Wrong time error & $1.9(21)$ & $0.6(7)$ & $0.35(0.15,0.84)$ & $\begin{array}{l}\text { Intravenous amoxicillin/clavulanic } \\
\text { acid given } 2 \mathrm{~h} \text { late }\end{array}$ \\
\hline Total & $10.5(118 / 1122)$ & $6.1(72 / 1175)$ & $0.61(0.45,0.84)$ & \\
\hline Odds ratio $(95 \%$ & nultivariate logistic $r$ & With correctio & ders 'registered v & a \\
\hline Odds ratio can no & Iculated becau & value during one of th & dy periods. & \\
\hline
\end{tabular}


Table V. Potential clinical significance of administration errors

\begin{tabular}{|c|c|c|c|c|}
\hline Category $^{a}$ & $\begin{array}{l}\text { Frequency of errors for } \\
\text { system with traditional } \\
\text { medication chart (no. of } \\
\text { errors) }\end{array}$ & $\begin{array}{l}\text { Frequency of errors for } \\
\text { system with computerised } \\
\text { medication chart (no. of } \\
\text { errors) }\end{array}$ & Odds ratio $(95 \% \mathrm{Cl})^{\mathrm{b}}$ & Example \\
\hline $\bar{B}$ & $6.9(77)$ & $5.0(59)$ & $0.72(0.51,1.02)$ & Ferrous fumarate omitted \\
\hline C & $3.5(39)$ & $1.1(13)$ & $0.31(0.17,0.59)$ & Atenolol $25 \mathrm{mg}$ instead of $12.5 \mathrm{mg}$ \\
\hline D & $0.2(2)$ & $0.0(0)$ & c & $\begin{array}{l}\text { Doxycycline } 200 \mathrm{mg} \text { (first dose of therapy) } \\
\text { omitted }\end{array}$ \\
\hline Total & $10.5(118 / 1122)$ & $6.1(72 / 1175)$ & & \\
\hline \multicolumn{5}{|c|}{ a See 'Potential Clinical Significance' section in the 'Methods' for definition of categories. } \\
\hline \multicolumn{5}{|c|}{ b Odds ratio $(95 \% \mathrm{Cl})$ Chi-squared test. } \\
\hline \multicolumn{5}{|c|}{ c Odds ratio can not be calculated because of zero value during one of the study periods. } \\
\hline
\end{tabular}

wrote down the observations during drug administration and compared these with the original medication orders afterwards. Therefore, we believe the bias to be minimal.

Because our study consisted of two study periods, our major concern was the potential effect of the observation on the nurses' behaviour in the study period after the intervention. If the nurses were aware of the purpose of the observation, the administration error rate in the study period after the intervention could have been lower and resulted in a larger difference. However, it is known that when observation is non-obtrusive and non-judgemental, the subject will soon return to their normal pattern of activity following an initial period of $1-3$ hours. ${ }^{[22]}$

Another potential limitation of this study is the fact that we did not use times series analysis or a control ward to rule out the possibility of time trends. Therefore, the results found may be partially explained by a trend in error reduction not linked to the intervention. However, as we are not aware of any other interventions focused on medication safety in the study period, this seems unlikely.

On the other hand, observing drug prescribing and administration on one clinical ward with two different systems (i.e. using computerised medication charts and traditional medication charts) is of great interest. In fact, this method suppresses potential bias due to the comparison of two heterogenous systems, because prescribers, patients, nurses and drugs are comparable in both systems. A randomised clinical trial remains the preferred method to provide the ultimate evidence. However, randomising patients within one ward over two different systems is not feasible.
A final limitation is the lack of clinically relevant endpoints like days of admission, harm done to the patient or costs. However, the classification of errors into potential clinical significance can be seen as a measure for the severities of the errors.

Notwithstanding these limitations, our study is one of the few that shows the effect of an intervention to reduce medication errors in everyday practice. Such evaluations are not only helpful to demonstrate a positive effect of the intervention, but they can also show that aspects of the intervention need further optimisation. Thus, in our setting, the rise in administrative prescription errors after the intervention should lead to a layout change of the printed medication charts.

\section{Conclusion}

This observational study shows a significant reduction in clinically relevant, administration and (therapeutic) prescription error rates when applying a system using computerised medication charts that are updated daily compared with a system using traditional medication charts.

According to these data, there is the potential to improve the quality of the medication distribution process, even without the introduction of a CPOE system. Because CPOE systems are not yet available in most hospitals, the system described in this study can be implemented until such a time that they are.

\section{Acknowledgements}

We would like to thank Dr Evert Jan Bakker for his extensive assistance in the statistical analysis. 
No sources of funding were used to assist in the preparation of this study. The authors have no conflicts of interest that are directly relevant to the content of this study.

\section{References}

1. Kohn L, Corrigan J, Donaldson M, editors. To err is human: building a safer health system. Committee on Quality of Health Care in America. Institute of Medicine. Washington (DC): National Academy Press, 1999

2. Thornton PD, Simon S, Mathew TH. Towards safer drug prescribing, dispensing and administration in hospitals. J Qual Clin Pract 1999; 19: 41-5

3. Crane VS. New perspectives on preventing medication errors and adverse drug events. Am J Health Syst Pharm 2000; 57: 690-7

4. Bates DW, Boyle DL, Van der Vliet MB, et al. Relationship between medication errors and adverse drug events. J Gen Intern Med 1995; 10: 199-205

5. Van den Bemt PMLA, Egberts ACG, De Jong-van den Berg LTW, et al. Drug-related problems in hospitalised patients: a review. Drug Saf 2000; 22: 321-33

6. Kanjanarat P, Winterstein AG, Johns TE, et al. Nature of preventable adverse drug events in hospitals: a literature review. Am J Health Syst Pharm 2003; 60: 1750-9

7. Barker KN, Flynn EA, Pepper GA, et al. Medication errors observed in 36 health care facilities. Arch Intern Med 2002; 162 (16): 1897-903

8. Allan EL, Barker KN. Fundamentals of medication error research. Am J Hosp Pharm 1990; 47: 555-71

9. van den Bemt PMLA, Egberts ACG. Geneesmiddelgerelateerde problemen gedefinieerd en geclassificeerd. Bijwerkingen en medicatiefouten systematisch ingedeeld. Pharm Weekbl 2002; 137 (44): 1540-3

10. National Coordinating Council for Medication Error Reporting and Prevention. Categorizing medication errors [online]. Available from URL: http://www.nccmerp.org/medErrorCatIndex.html [Accessed $2002 \mathrm{Aug}$ ]

11. Kucukarslam SN, Peters M, Mlynarek M, et al. Pharmacists on rounding teams reduce preventable adverse drug events in hospital general medicine units. Arch Intern Med 2003; 163: 2014-8
12. Leape LL, Cullen DJ, Clapp MD, et al. Pharmacists participation on physician rounds and adverse drug events in the intensive care unit [published erratum appears in JAMA 2000; 283 (10): 1293]. JAMA 1999; 282 (3): 267-70

13. Kaushal R, Shojania KG, Bates DW. Effects of computerized physician order entry and clinical decision support systems on medication safety: a systematic review. Arch Intern Med 2003; 163 (17): 1409-16

14. Fontan JE, Maneglier V, Nguyen VX, et al. Medication errors in hospitals: computerized unit dose drug dispensing system versus ward stock distribution system. Pharm World Sci 2003; 25 (3): $112-7$

15. Dean B, Schachter M, Vincent C, et al. Prescribing errors in hospital inpatients: their incidence and clinical significance. Qual Saf Health Care 2002 Dec; 11 (4): 340-4

16. Lesar TS, Briceland SL, Delcourse K, et al. Medication prescribing errors in a teaching hospital. JAMA 1990; 263 (17): 2329-34

17. Tissot E, Cornette C, Limat S, et al. Observational study of potential risk factors of medication administration errors. Pharm World Sci 2003; 25 (6): 264-8

18. Taxis K, Dean B, Barber N. Hospital drug distribution systems in the UK and Germany: a study of medication errors. Pharm World Sci 1999; 21 (1): 25-31

19. Van den Bemt PMLA, Fijn R, Van der Voort PHJ, et al. Frequency and determinants of drug administration errors in the intensive care unit. Crit Care Med 2002; 30 (4): 846-50

20. Flynn EA, Barber KN, Pepper GA, et al. Comparison of methods for detecting medication errors in 36 hospitals and skillednursing facilities. Am J Health Syst Pharm 2002; 59: 436-46

21. Dean B, Barber N. Validity and reliability of observational methods for studying medication administration errors. Am J Health Syst Pharm 2001; 58: 54-9

22. Barker KN. Data collection techniques: observation. Am J Hosp Pharm 1980; 37: 555-71

Correspondence and offprints: Dr Dieuwke G. van GijsselWiersma, Hospital Pharmacy, Slingeland Hospital, Postbus 169, 7000 AD Doetinchem, The Netherlands.

E-mail: d.van.gijssel@slingeland.nl 